\title{
MAL-ESTAR CIVILIZATÓRIO E ÉTICA DA COMPREENSÃO
}

Edgard de Assis Carvalho

Professor do Departamento de Antropologia da PUC-SP

$\mathrm{A}$ construção de uma ética para o futuro demandará um esforço de proporções incomensuráveis e reunirá todos aqueles que acreditam nas forças de conjunção, que solidarizam, fraternizam e universalizam. Será preciso, certamente, exercitar a futurologia, não entendida obviamente como uma forma de irracionalismo, mas como um modo de entendimento, uma ecologia cognitiva que torne possível estabelecer um horizonte prospectivo para a vida, as idéias e a cultura planetárias, nesses tempos sombrios de globalizações técnicas e ressurgimentos étnicos exterminadores.

Hans Jonas, em Para uma ética do futuro (1998), afirmou serem necessárias duas tarefas preliminares a ser levadas a cabo por todos os humanos que investem energia libidinal na boa utopia de um mundo menos antropocêntrico e mais ecocêntrico: a primeira, a maximização do conhecimento das consequiências de todos os nossos agires, dada a agonia planetária que acomete a todos nós; a segunda, a elaboração de uma forma de conhecimento transdisciplinar, que fosse capaz de conjugar saberes fatuais e saberes axiomáticos.

Para isso, a fabricação do real teria de se pautar pela combinação do intelecto com a emoção, do necessário e do contingente, da harmonia e do caos. Essa modalidade renovada de consciência coletiva, destituída de qualquer intenção prometeica, seria saturada de complexus, ou seja, de agires e fazeres que rejuntariam tudo aquilo que a disjunção cartesiana se incumbiu de separar no plano físico, metafísico e metapolítico. Qualquer sistema vivo passaria, então, a ser entendido como um sistema incompleto, indeterminado, irreversível, sempre marcado pela auto-organização que combina, descombina e recombina a ordem, a desordem, a reorganização.

Mas é evidente que se estabelece um abismo entre o fato e o axioma, ainda mais quando nos defrontamos com a proposição de uma ética da solidariedade transnacional, articulada a uma ética dos direitos individuais. É conveniente lembrar que ética, em grego ethos, significa a morada humana, a casa comum, a Terra-Pátria-Mátria, que clama por um projeto de sustentabilidade, uma "política de civilização" que seja capaz de reintegrar o cosmos, a matéria, a vida, o homem.

O problema não é novo na cultura política e isso porque sabemos, desde Freud, que o obstáculo maior a uma antropolítica civilizatória plena esbarra sempre na hostilidade primária que joga homens contra homens numa onda crescente de violência, na qual as paixões instintivas individuais pesam mais que qualquer tentativa de promover um modelo de homem que expresse a realização concreta do humanismo - necessidade que impregna as idéias de Morin desde os anos 70.

Essa espiral de pulsões humanas, saturadas de agressão e autodestruição, é comandada pelos "novos senhores do mundo": uma elite poliforme que engloba os quadros da tecnociência, da tecnoburocracia nacional e internacional, financistas, patrões dos meios de comunicação, redes de traficantes transnacionais, além de estrelas de TV, esporte e moda e dirigentes mercadológicos de seitas religiosas. Nesse teatro de crueldades, a dominação da natureza e da cultura foi levada a um extremo de proporções incontroladas e, por extensão, o extermínio de outros homens, e, por que não dizer, de nações e do pró- 
prio planeta, passou a ser entendido de forma naturalizada. Se, já em 1929, quando Freud escreveu O mal-estar da civilização, essa advertência contra a barbárie ressoava forte sobre os destinos da Europa, hoje, 79 anos mais tarde, elas se revelam mais atuais do que nunca para o planeta.

O que se constata é o congelamento da condição humana num cinismo narcísico e numa indiferença programada, que acaba produzindo imagens de autodefesa de tal ordem que o que passa a importar é uma hipervalorização da segurança doméstica, em todas as dimensões que a expressão possa conter. Com isso, forja-se um consentimento, velado ou não, diante do conjunto das "políticas do mal", perpetradas por sistemas totalitários, e mesmo democráticos, para os quais a geopolítica se reduz a uma territorialidade diabólica capitaneada por essa invenção européia que é o Estado-Nação com seus códigos, suas práticas, suas instituições que se incumbem de atualizar o mito do pertencimento e da comunidade de destino.

Pode até parecer paradoxal que toda essa religiosidade do Estado-Nação ainda seja muito forte nesses tempos de desterritorialização dos fluxos do capital e das riquezas. Como acredita Sami Naïr (1997), o mito nacional parece transcender qualquer idealidade ou materialidade, mesmo que a mundialização do liberalismo venha subvertendo os fundamentos confessionais da soberania, expressos na identidade simbólica territorial.

Mundialização/globalização são expressões cercadas de ambigüidade, porque põem o diabo dentro de casa, travestido de anjo anunciador de novas esperanças e mensagens, ou seja, carrega consigo uma abertura para o universal e um fechamento para o particular regressivo, assim como uma inclusão pelos mecanismos perversos do mercado, aliada a uma exclusão multiforme pelo desemprego, pela fome, pela miséria, pela cultura.

Apesar de tudo isso, o planeta, longe de ser um sistema global, ou de se constituir numa nova ordem mundial, comporta-se como um turbilhão em movimento desprovido de um centro organizador, cuja hegemonia é sempre provisória, constitutivo de um mundo policêntrico, incerto, caótico e frágil. Talvez seja possível utopizar uma ética civilizatória entendida como nova filosofia pública, uma polifonia de valores e culturas constantemente retroaliamentada pela dialogia entre ciência e tradição, entre imaginário e real, entre subjetividade e objetividade, entre oriente e ocidente.

Essa dialogia, pautada por uma espécie de ética da tolerância prática, terá que repropor uma nova coalizão de cul- turas que não seja capitaneada pelo progressismo tecnológico do Ocidente, fundado no antropocentrismo contido nas múltiplas formas de dominação da natureza. Essa coalizão deverá estar fundada numa perspectiva ecocêntrica, do grego oikos, lar, para a qual lar/Terra, ou o meioambiente planetário, será a baliza a partir da qual se poderá - e se deverá - pensar a relação homem/natureza, homem/mundo, como unidualidade permanente e necessária.

Mas o conceito de tolerância é igualmente ambíguo, dada a própria etimologia da palavra. Tolerar pode significar sofrer, suportar pacientemente, assim como denotar a ação de erguer, de ter vigor para enfrentar dificuldades.

Seu advento e reconhecimento como paz civil e garantia contra a injustiça foi obra de filósofos capitaneados por Diderot, Rousseau e, principalmente, Voltaire. Seu Tratado sobre a tolerância, escrito em 1763, expressa, de modo soberbo, a tensão humana entre a tolerância e o fanatismo, entre culturas que se pretendem equivalentes e identidades que se objetivam na tirania e na violência mimética.

Se o espaço da tolerância pode abrigar a afirmação e o reconhecimento do outro, desde que ele permaneça em condição subalterna e não colida com o núcleo central das identidades sociopolíticas, como prega a perversidade relativista e diferencialista, ele também pode significar abertura para novas conexões, estilos societários e processos de transformação cultural.

Talvez o conteúdo básico da ética de tolerância prática precise investir mais na interdependência, na não-linearidade, na realimentação, na cooperação e na parceria aberta das culturas planetárias. Mesmo que se discorde de posições que apontam a Ásia como o palco privilegiado das ações geosociopolíticas, apesar dos pesares, por conseguir articular tecnologias ocidentais e filosofia oriental, é possível prever que uma ética da tolerância intercivilizatória formada a partir da conjunção de tradições orientais e ocidentais, venha a ser, finalmente, capaz de combinar mundialização e diversidade cultural, ou, em outras palavras, perceber que a diferença tem sempre a ver com a complexidade da rede Terra integrante da teia geral da vida. Fixar-se obstinadamente no diferencialismo implica sempre abstrair-se do fluxo geral da vida, de uma parte dela, colocar-se nas fronteiras tribais como um sentinela irascível que pretende transfigurar o outro em simplesmente outro.

O relativismo enquanto visão de mundo foi a expressão mais acabada dessa complacência moralista, uma espécie de embriaguez de diversidade cultural e de expia- 
ção dos pecados do colonialismo, como bem frisou Ernest Gellner (1994). O maior efeito dessa postura foi a proliferação das chamadas etnografias densas que pretendem traduzir as culturas como textos cujos significados nem sempre são decifráveis, dada a desconfiança mútua que se instala entre uma subjetividade que cria o mundo, outra que cria o texto sobre esse mesmo mundo e uma terceira que lê e ouve o produto desse encontro desencantado e niilista. Como uma versão pós-moderna e desencantada do velho funcionalismo, o relativismo só serve mesmo para expor o mal-estar da cultura, enxergando simetrias e equivalências onde só existem assimetrias e dominações. Trata-se de "uma paródia total e desastrosa do mundo em que vivemos. Todos aqueles que a aprovam não podem sequer começar a compreender a condição humana atual" (Gellner, 1994:89).

Fritjof Capra, em seu último livro, A teia da vida (1996), sustenta que qualquer comunidade ecológica diversificada é uma comunidade elástica e não estática. Esse é o papel que a diversidade étnica e cultural poderia vir a desempenhar, o de abrir-se para o mundo, de tornar-se tolerante consigo mesma e com os outros, reciclando-se constantemente em direção à construção de uma "consciência cívica terrestre", ou seja, a consciência de habitar, com todas as extraordinárias diversidades individuais e culturais, uma mesma esfera humana.

Para isso, torna-se urgente reconciliar universal e singular, nacional e local, parte e todo, levando-se em conta o jogo das interdependências e contradições e de sua evolução no tempo e no espaço. Além disso, será preciso efetivar duas refundações prioritárias: a do homem e a do pensamento. Mas que significa refundar o homem? Em primeiro lugar, é preciso ter humildade. Jung, em 1928, afirmava que essa humildade implicava reconhecer que se hoje "o homem moderno está no ápice, amanhã estará superado" (Jung, 1988). Resultante de uma evolução antiquíssima, é a pior desilusão de todas as esperanças da humanidade. Esse mesmo homem sabe muito bem que a ciência, a técnica e a organização podem ser uma benção, mas sabe também que podem ser catastróficas.

Depois de 71 anos, essas ponderações soam muito mais do que oportunas, pois esse homem que perdeu todas as certezas metafísicas, desde a Idade Média, está lançado no manancial das incertezas e das dissipações, mesmo que cercado de seguranças materializadas e esperanças virtualizadas. Embriagado pelo tempo real, tenta equilibrarse no espaço multiforme de guerras planetárias e limpezas étnicas regressivas, em que se movem contraditoria- mente construção e destruição, civilização e barbárie, pulsão de vida e pulsão de morte.

A distinção feita por Lévi-Strauss revela-se mais do que oportuna para esses tempos sombrios de final de milênio. Para ele, duas constelações estruturais básicas vitalizam a condição humana; as culturas antropofágicas, que introjetam, absorvem e devoram, e as culturas antropoêmicas, que vomitam, ejetam, expulsam. A cultura contemporânea hipermoderna soube como ninguém cometer um crime perfeito, ao realizar a síntese radical dessas duas culturas, representada pelas formas mais avançadas de integração e por fluxos infinitos de expulsão. Esse "crime perfeito", feliz expressão de Baudrillard para designar a corrosão do caráter, revela-se apropriado para designar uma outra "morte do homem", decretada dessa vez pela hiper-realidade das máquinas. "No lugar da morte, a eternidade do chip, no lugar do corpo, a plástica das partes, no lugar de cada um, a clonagem das células" (Baudrillard, 1994:57).

Desde Jung, portanto, percebe-se que a consciência deveria voltar-se para o homem, em sua realidade mais interna e subjetiva para, a partir daí, identificar as fontes do mal que atingem, indistintamente, a todos nós. O homem ocidental construiu um mundo tão autocentrado que não consegue objetivar-se verdadeiramente como um sapiens-demens, ao mesmo tempo sábio e louco. Vive antes uma vida prosaica, submersa na racionalidade utilitária e maquínica, do que uma vida poética explicitada no amor, na sabedoria, na meditação, no êxtase e nas explosões imaginais (Morin, 1998).

É mais galinha, confinado em seu espaço territorial, ciscando aqui e ali sua ração cotidiana, do que águia, que voa para o infinito indeterminado até confundir-se com o azul do firmamento. Neste aspecto, concordamos com as idéias de Leonardo Boff (1997) sobre essas metáforas da condição humana, que nos impele à multiplicidade, ao mesmo tempo em que nos aprisiona na perplexidade narcísica do ego.

O Ocidente que, para Spengler, estaria voltado à decadência inevitável, porque submetido à segunda lei da termodinâmica, soube redirecionar sua história material, deixando de lado o mundo da psique e da alma. Não criou um neo-homem, como não criará um neo-socialismo ou uma neocultura, como acreditam alguns. Consagrou, isso sim, o homem dualista, que nunca rejunta prosa e poesia, que nunca consegue ser, simultaneamente, galinha e águia, que não concede espaço para seus demônios, suas vozes interiores e superiores. 
Mas, as contracorrentes, que estão aí para quem quiser ver, criticar e descrer, que rejeitam qualquer idolatria de mão única e se situam nas brechas dessa mesma história material, pretensamente unidimensional e eterna, indicam que a esperança não morreu, que a utopia não é a expressão de um topos negativo e, muito menos, o mundo prometeico, no qual as necessidades gerais estariam plenamente satisfeitas. A utopia possível, e passível de realização, implica uma "política de civilização", fundada na "ética cívica planetária", que abra espaço para a complexidade da criatividade humana.

Para isso, é imperioso praticar a auto-ética, como uma espécie de arte articulada à ética política, construída a partir de seis idéias-guia que, para Morin, são fundamentais para a "restauração do sujeito responsável": a ética do religamento, a ética do debate, a ética da compreensão, a ética da magnanimidade, a ética da resistência e a incitação às boas vontades (Morin, 1998:65-77).

Em nosso entender, esse ideário pode ser concebido como um arquétipo, ou seja, uma forma irrepresentável e inconsciente que sempre existiu, mas que perdeu sua capacidade de influenciar os comportamentos humanos. Como força energética, precisa ressincronizar-se, readquirir voz, manifestar-se como fenômeno cognitivo, fazer jus à natureza psicóide do arquétipo que aponta para o unus mundus (o mundo unitário), circundado por uma responsabilidade coletiva generalizada, capaz de construir uma ética societal que respeite o homem, a vida e a liberdade planetárias, e estimular a consciência de pertencimento à Terra-Pátria.

Se o medo, o desespero-pânico e a revolta moral possibilitam a eclosão de reações pontuais contrárias aos desmandos sociais que proliferam por todos os poros da vida social, por vezes podem vir a contribuir para a ampliação do caos, como se estivéssemos todos projetados num buraco negro resultante do desmoronamento da vida. Como todo caos acaba sempre por liberar a matéria de sua inércia, é possível supor que criatividades, improvisações e imaginários políticos grandiosos possam ser capazes de refabricar a aliança entre o homem e o cosmos, representada desta vez por um conjunto de universos múltiplos que instituam a condição humana como comunidade organizada em torno de uma autêntica ética planetária, mesmo que se admita que o próximo século será dominado pela transferência de tecnologias de informação e por estratégias organizatórias complexas e contingentes conduzidas por máquinas espirituais.
O cansaço de Gaia é patente perante a magnitude da arquitetura da destruição que vem se desenhando há três bilhões de anos no planeta. "Sabemos que, se desejarmos continuar a viver na Terra com saúde e conforto, deveremos também manter Gaia saudável" (Freeman, 1998:125). Essas palavras de Dyson reiteram que o equilíbrio de Gaia é fundamental para a coexistência ética dos humanos, mesmo que seja impossível prever em que horizonte histórico e evolutivo esse cenário será concretizado, dado que as "novas eras" serão operadas pela informação, pela biotecnologia e pela neurotecnologia. Somente vitórias éticas e virtudes públicas terão força para comprometer o lado inumano da tecnologia e buscar a ampliação de uma justiça social de caráter planetário.

Mas é imperioso que se tenha em mente, como sempre ressalta Prigogine (1997:61-84), que o homem vive sempre duas experiências cruciais: a da repetição, que propicia as construções de determinismos desde Newton; e a da criatividade da arte, da literatura, do imaginário, que reinventa o mundo, no oceano tormentoso da ordem/desordem/reorganização. Ainda é tempo de promover uma revolução radical capaz de superar o dualismo entre matéria e vida, para que seja possível enfrentar a propagação do conformismo que o liberalismo tecnomidiático está veiculando através de um espaço mundializado, constituído por regimes globalitários. Talvez com isso seja possível, finalmente, reapropriar o sujeito enquanto multiplicidade e unidade, de um trajeto antropológico cujo fim permanecerá sempre desconhecido e indeterminado.

Se a vida é sonho, e se sonho é sempre realização de um desejo inconsciente, sonhemos todos com Dostoiévski que, em sua narrativa fantástica $O$ sonho do homem ridículo, antecipou de modo arrebatador a imperiosidade de uma nova organização do mundo fundada não apenas na frieza da razão fechada, mas na polifonia complexa da memória, dos arquétipos, dos mitos, dos deuses, dos sentimentos e das emoções capazes de transfigurar lindamente a natureza e a cultura. "Ama a humanidade como a ti mesmo! Isso é tudo e nada mais é preciso; saberás depois como hás de viver. E, além disso, só há uma verdade... uma verdade antiga, antiquíssima, mas que é preciso repetir uma e mil vezes e que até agora não se arraigou em nossos corações. O conhecimento da vida está acima da vida; o conhecimento da lei da felicidade está acima da própria felicidade. Eis aí aquilo contra que se deve lutar. E eu lutarei contra isso! Se todos quisessem, tudo mudaria sobre a terra num momento." 


\section{NOTA}

E-mail do autor: edgard@pratanet.com.br

\section{REFERÊNCIAS BIBLIOGRÁFICAS}

BAUDRILLARD, J. Le crime parfait. Paris, Galilée, 1994.

BOFF, L. A águia e a galinha. Petrópolis, Vozes, 1997.

CAPRA, F. The web of life. A new synthesis of mind and matter. London, Harper Collins, 1996.

DOSTOIÉVSKI, F.M. O sonho de um homem ridículo. In: Obras Completas. Trad. Natália Nunes. Rio de Janeiro, Nova Aguilar, v.IV, 1995, p.1.230.

FREEMAN, D. Mundos imaginados. São Paulo, Companhia das Letras, 1998 (tradução Cláudio W. Abramo).
FREUD, S. El mal estar en la cultura. Madrid, Biblioteca Nueva, 1981 (Obras Completas, v.III, p.3.017-3.100).

GELLNER, E. Posmodernismo, razón y religión. Barcelona, Paidós, 1994.

JONAS, H. Para uma ética do futuro. Paris, Payot, 1998 (tradução Sabine Cornille e Philippe Ivernel).

JUNG, C.G. Presente e futuro. Petrópolis, Vozes, 1988 (tradução Márcia Cavalcanti).

MORIN, E. "A ética do sujeito responsável”. In: Ética, solidariedade e complexidade. São Paulo, Palas Athena, 1998.

. Amor, poesia, sabedoria. Rio de Janeiro, Bertrand Brasil, 1998 (tradução Edgard de Assis Carvalho).

NAÏR, S. "La mondialisation du libéralisme économique". In: MORIN, E. e NAÏR, S. Une politiqué de civilisation. Paris, Arléa, 1997, p.39-106.

PRIGOGINE, I. "La fin da la certitude". In: MENDES, C. (org.). Réprésentation et complexité. Rio de Janeiro, Universidade Cândido Mendes, 1997. 